American Journal of Applied Sciences 9 (7): 1037-1045, 2012

ISSN 1546-9239

(C) 2012 Science Publications

\title{
Thermal Comfort Assessment-A Study Toward Workers' Satisfaction in a Low Energy Office Building
}

\author{
Mohd Nafiz Shaharon and Juliana Jalaludin \\ Department of Environmental and Occupational Health, \\ Faculty of Medicine and Health Sciences, \\ Universiti Putra Malaysia (43400), Serdang, Malaysia
}

\begin{abstract}
Problem statement: The government of Malaysia has raised their concerns towards the issue of workers comfort and workspace quality in a Low Energy Office (LEO) building. New energy efficient building concepts and technologies require a revision of comfort standards, to create a suitable thermal condition in avoiding occupant dissatisfaction, adverse effect on their productivity and overall building performance. Approach: Assessment was conducted using Babuc-A (Portable air quality monitor) and sets of questionnaire adapted from ASHRAE-2004 were 99 respondents selected using a stratified random sampling. Results: This study shows that the thermal comfort zone temperature was identified to be within the range of $21.6-23.6^{\circ} \mathrm{C}$ and relative humidity of $42-54 \%$. Conclusion: The results suggested that the thermal condition was in the acceptable range of ISO7730 and a lower room temperature was preferred by Malaysian in an office environment compared with the temperature criteria cited in ASHRAE-55. To create an optimum comfortable workplace, temperature between $20-26^{\circ} \mathrm{C}$ and relative humidity between $40-60 \%$ must be maintained. Adequate ventilation must be provided at the minimum rate of $10 \mathrm{l} / \mathrm{s}$ of fresh air per person for general office space or every $10 \mathrm{~m}^{2}$ of floor space.
\end{abstract}

Key words: Thermal comfort, satisfaction, low energy office, natural ventilation, PMV, PPD

\section{INTRODUCTION}

British Standard BS EN ISO 7730 (ISO 7730, 1994) defines the term 'Thermal comfort' as: 'that condition of mind which expresses satisfaction with the thermal environment.'

Thermal comfort was defined by the American Society of Heating, Refrigeration and Air-Conditioning Engineers (ASHRAE) as that state of mind which expresses satisfaction with the thermal environment (ASHRAE, 2009). Though it is difficult to satisfy everyone in a space due to physiological and psychological variation from person to person, thermal comfort is still one of the most significant factors affecting environmental satisfaction (Nazanin et al., 2008). According to Chen et al. (2006), there are seven major factors which are, dry bulb temperature, water vapor pressure, air velocity, radiant temperature; virtually all the Heating, Ventilating and AirConditioning (HVAC) system, metabolic rate, clothing and the length of time exposure (Sherman, 1985). Thermal comfort was measured by the number of employees complaining of thermal discomfort (HSE, 2008).

Furthermore, the 'feeling comfortable' was very subjective in nature and cannot be defined objectively. Frequent changes in arrangement in office space and the huge amount of the cables brought about by the extensive use of computers make the implementation of air conditioning office a necessity (Wan and Chao, 2002). Naturally ventilated building designs can perform efficiently in a hot climate country like Malaysia because of their low evaporation rate, long hours of sunshine, high relative humidity and very overcast cloud cover. As a country that is progressing towards an energy consumption conscious target, buildings are designed to enable natural ventilation (Dahlan et al., 2008). Results of a study in Germany, which was conducted on workplace occupant satisfaction in 16 office buildings revealed that the occupants' control of the indoor climate and moreover the perceived effect of their intervention strongly influences their satisfaction with the thermal indoor quality (Wagner et al., 2007).

Corresponding Author: Juliana Jalaludin, Department of Environmental and Occupational Health, Faculty of Medicine and Health Sciences, Universiti Putra Malaysia (43400), Serdang,

Malaysia Tel: +603 - 89472401 Fax: +603 - 89450151 
To enable a researcher to improve the thermal comfort in the workplace, the six parameters contributing to thermal comfort were measured and calculated using Fanger (1970) comfort model. This model which was based on Predicted Mean Vote (PMV) and Predicted Percentage Dissatisfied people (PPD) index and used of BS EN ISO 7730 and BS EN ISO 10551 British standards are recommended (HSE, 2008).

Overall, the study on thermal comfort emphasize the importance of thermal comfort for office occupants and highlight that achieving thermal comfort in offices not only delivers more satisfaction for the occupants, but also improves their performance (Nazanin et al., 2008).

\section{MATERIALS AND METHODS}

Location: The location of this study was conducted in a Low Energy Office (LEO) Buowning, own by the Ministry of Energy, Green Technology and Water, Malaysia. This LEO building is the first government building of its kind to be built with integrated energy efficient design.

Selection of respondents: A stratified random sampling was used for respondents' selection of this study and it was estimated that $80 \%$ of occupants at each sampling location involve in this study. Respondents were selected based on the inclusion criteria which workers at each location worked in a low and high-occupancy, larger open plan rooms in the building, including both male and female within the age of 20-40 years old (young adults), having normal BMI and currently in healthy status and doing a desk-based job (Khalil and Husin, 2009). Because the human body has its own temperature regulating responses (e.g., sweating, vasodilatation/constriction, shivering), an occupants' response to (and hence sensation of) the environment will be a strong function of his/her physical condition and a young, healthy body recovers more quickly and therefore can respond to changes in thermal stress more quickly than can an older, illconditioned one (Sherman, 1985).

Sampling methods: Numbers of 99 respondents, which are the staffs in the Ministry of Energy, Green Technology and Water, Malaysia, were selected based on the location with the high numbers of workers located to be involved in the survey. Two types of approaches were conducted in collecting the data which are the physical quantities instruments and workers' satisfaction survey.
Physical quantities instruments: Physical quantities instruments were an objective approach in data collection. This approach involves the use of mechanical devices in collecting data. Four environmental parameters were measured using physical quantities instruments (Babuc A) which were dry bulb temperature, relative humidity, radiant temperature and air velocity (Wagner et al., 2007). The data gathered from this equipment were processed using LSI programs. Physical measurements were taken at the height of 1.1 meters (Daghigh et al., 2009) above the floor, which represents the height of the occupant at seated level. The sample was recorded in every $30 \mathrm{sec}$ interval for $1 \mathrm{~h}$. Having measured the environmental parameters, metabolic rate and clothing insulation were estimated in accordance with ISO 7730 and ASHRAE Standard-55. In this study, the metabolic rate was set to be 1.2 met which are sedentary activities (office, dwelling, school and laboratory) and the Clo-values were calculated to be 0.87 .

Workers' satisfaction survey: Subjective thermal comfort data were recorded using a questionnaire adapted from ASHRAE (2004). A questionnaire survey that is simple and designed to seek occupant input for the level, the frequency and the time of the thermalcomfort problem as well as the general conditions of the thermal environment can greatly help in defining the pattern of complaints and distribution in terms of time and space (Budaiwi, 2007).

Data analysis: All the physical measurements of the environment under studied were analyzed using InfoGap v.2.0.6 and Microsoft Excel v. 2007 whereas data from the surveys was analyzed using Statistical package for Social Science (SPSS) ver. 15. Analysis for this researched was divided into four sections:

- Results of the questionnaire survey

- Results of the physical measurements

- Comparison between questionnaire and physical measurement

- Compliance with ASHRAE (2004) and ISO 7730 (1994)

\section{RESULTS}

Instrument results: There were five days of where the measurement took its place and in each day, three sampling points were selected which ends up to be 15 sampling points for this total study. The results of indoor temperatures during the study period were given in Table 1. 
Am. J. Applied Sci., 9 (7): 1037-1045, 2012

Table 1: Result of indoor thermal measurement

\begin{tabular}{|c|c|c|c|c|c|c|c|c|}
\hline & & $\begin{array}{l}\text { TeAIR } \\
\left({ }^{\circ} \mathrm{C}\right)\end{array}$ & $\begin{array}{l}\text { TeWET BULB } \\
\left({ }^{\circ} \mathrm{C}\right)\end{array}$ & $\begin{array}{l}\text { TeDRY BULB } \\
\left({ }^{\circ} \mathrm{C}\right)\end{array}$ & $\begin{array}{l}\text { TeGLOBE } \\
\left({ }^{\circ} \mathrm{C}\right)\end{array}$ & $\begin{array}{l}\text { Rel HUM } \\
(\%)\end{array}$ & $\begin{array}{l}\text { AIRVel } \\
(\mathrm{m} / \mathrm{s})\end{array}$ & $\begin{array}{l}* \mathrm{MRT} \\
\left({ }^{\circ} \mathrm{C}\right)\end{array}$ \\
\hline \multirow[t]{3}{*}{ Floor 1} & Point 1 & 23.15 & 15.61 & 22.02 & 22.89 & 49.18 & 0.018 & 22.81 \\
\hline & Point 2 & 23.52 & 15.83 & 22.57 & 23.30 & 47.63 & 0.070 & 23.16 \\
\hline & Point 3 & 23.61 & 15.76 & 22.59 & 22.59 & 47.01 & 0.030 & 22.17 \\
\hline \multirow[t]{3}{*}{ Floor 2} & Point 1 & 21.75 & 15.30 & 20.80 & 21.52 & 54.31 & 0.022 & 21.44 \\
\hline & Point 2 & 22.82 & 14.38 & 21.76 & 22.41 & 42.09 & 0.006 & 22.33 \\
\hline & Point 3 & 22.11 & 14.18 & 21.34 & 21.73 & 42.96 & 0.021 & 21.60 \\
\hline \multirow[t]{3}{*}{ Floor 3} & Point 1 & 22.45 & 14.46 & 21.70 & 22.10 & 42.92 & 0.019 & 21.98 \\
\hline & Point 2 & 22.34 & 14.58 & 21.62 & 22.03 & 44.18 & 0.011 & 21.95 \\
\hline & Point 3 & 22.36 & 14.43 & 21.49 & 21.92 & 44.76 & 0.015 & 21.79 \\
\hline \multirow[t]{3}{*}{ Floor 4} & Point 1 & 23.11 & 15.71 & 22.04 & 22.87 & 49.79 & 0.013 & 22.80 \\
\hline & Point 2 & 23.2 & 15.67 & 22.10 & 22.95 & 49.16 & 0.010 & 22.89 \\
\hline & Point 3 & 23.13 & 15.58 & 22.11 & 22.96 & 48.41 & 0.025 & 22.90 \\
\hline \multirow[t]{3}{*}{ Floor 5} & Point 1 & 22.01 & 15.41 & 21.01 & 21.75 & 53.81 & 0.024 & 21.65 \\
\hline & Point 2 & 21.68 & 15.07 & 20.67 & 21.36 & 53.38 & 0.012 & 21.28 \\
\hline & Point 3 & 21.63 & 15.14 & 20.68 & 21.35 & 53.89 & 0.026 & 21.24 \\
\hline
\end{tabular}

* MRT $=$ Mean Radiant Temperature

Table 2: Results of calculating operative temperature, PMV and PPD

\begin{tabular}{llcl}
\multicolumn{1}{c}{ values } & & & \\
\hline----- Locations-- & & PMV \\
\hline FLOOR 1 & Point 1 & 0.2 & 5.8 \\
& Point 2 & 0.3 & 6.9 \\
FLOOR 2 & Point 3 & 0.2 & 5.8 \\
& Point 1 & 0.1 & 5.2 \\
FLOOR 3 & Point 2 & 0.0 & 5.0 \\
& Point 3 & -0.1 & 5.2 \\
& Point 1 & 0.0 & 5.0 \\
FLOOR 4 & Point 2 & 0.0 & 5.0 \\
& Point 3 & 0.0 & 5.0 \\
FLOOR 5 & Point 1 & 0.2 & 5.8 \\
& Point 2 & 0.2 & 5.8 \\
& Point 3 & 0.2 & 5.8 \\
& Point 1 & -0.1 & 5.2 \\
& Point 2 & -0.1 & 5.2 \\
& Point 3 & -0.2 & 5.8 \\
\hline
\end{tabular}

Based on the table, the parameters measured were dry bulb, wet bulb, globe temperature, relative humidity and air velocity as the main parameters needed in calculating the thermal comforts PMV and PPD values. The air temperature recorded in the measurement range between $23.61^{\circ} \mathrm{C}$ as the highest reading to the lowest of $21.63^{\circ} \mathrm{C}$. The radiant temperature inside this table was calculated based on the given equation by MJKKP (2005):

$\mathrm{T}_{\mathrm{mrt}}^{4}=\mathrm{T}_{\mathrm{g}}^{4}+\mathrm{C} \sqrt{\nabla}\left(\mathrm{T}_{\mathrm{g}}-\mathrm{Ta}\right)$

Where:

$\mathrm{T}_{\text {mrt }}=$ Mean radiant temperature

$\mathrm{K}, \mathrm{T}_{\mathrm{g}}=$ Globe temperature

$\mathrm{K}, \mathrm{T}_{\mathrm{a}}=$ Ambient air temperature, $\mathrm{K}$

$\mathrm{V}=$ Air velocity, $\mathrm{m} / \mathrm{s}$

C $\quad=0.247 \times 10^{9}$
Human thermal comfort is influenced by psychological as well as physiological factors. Several comfort indices, such as PMV and PPD have been developed. These indices attempt to correlate human thermal comfort with environmental conditions. The PMV index predicts the mean response of a large group of people exposed to a certain environment following 7point thermal sensation scale according to the ASHRAE. PMV was established from the physics of heat transfer combined with an empirical fit to sensation and thermal strain based on steady-state heat transfer between the body and the environment and assigns a comfort vote to that amount of strain (ASHRAE, 2009). PPD is the predicted percent of dissatisfied people at each PMV. As PMV changes away from zero in either the positive or negative direction, PPD increase.

The calculation of the PMV and PPD in Table 2 was done by using a software program named PMVcalc version 2.0, which was modified by Håkan Nilsson from the Department of Technology and Built Environment, Laboratory of Ventilation and Air Quality University of Gävle as well as Microsoft Excel (Fig. 1). PMV and PPD were calculated based on the combined results of physical measurement and observation of the type of activity and clothing.

Thermal response vote: Figure 2 showed the distribution of thermal sensation votes, most of which range from -1 (Slightly cool) to 1 (slightly warm) and $63.6 \%$ of the respondents perceive thermal sensation as neutral. It indicates that most of the occupants adjusted for the climatic variation and remained satisfied with the indoor thermal environment. 


\begin{tabular}{|l|c|}
\hline Parameter & Input \\
\hline Clothing (clo) & \\
\hline Air temp ( $\left.{ }^{\circ} \mathrm{C}\right)$ & \\
\hline Mean radiant temp. $\left({ }^{\circ} \mathrm{C}\right)$ & \\
\hline Activity (met) \\
\hline Air speed (m/s) \\
\hline Relative humidity (\%) \\
\hline \multicolumn{2}{|c|}{ Calculate PMV } \\
\hline Parameter \\
\hline Operative temp. ( $\left.{ }^{\circ} \mathrm{C}\right)$ & Results \\
\hline PMV & 23 \\
\hline PPD & 0.0 \\
\hline
\end{tabular}

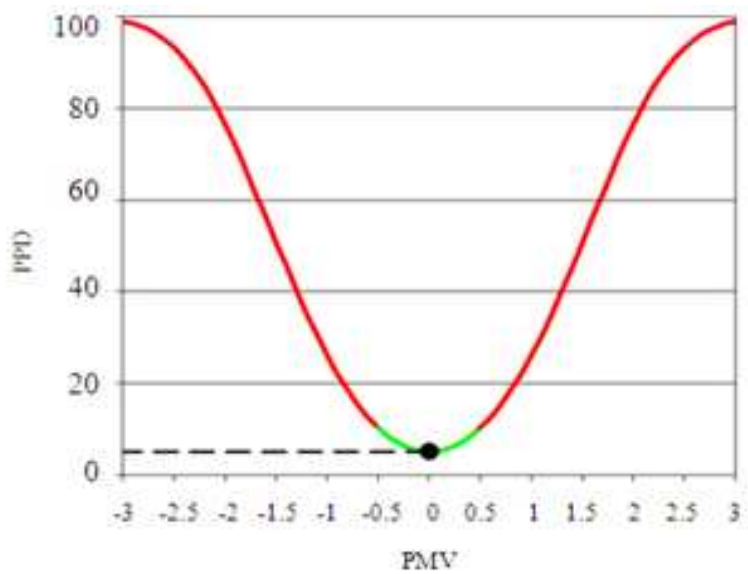

Fig. 1: PPD as a function of PMV (ISO 7730) for each location

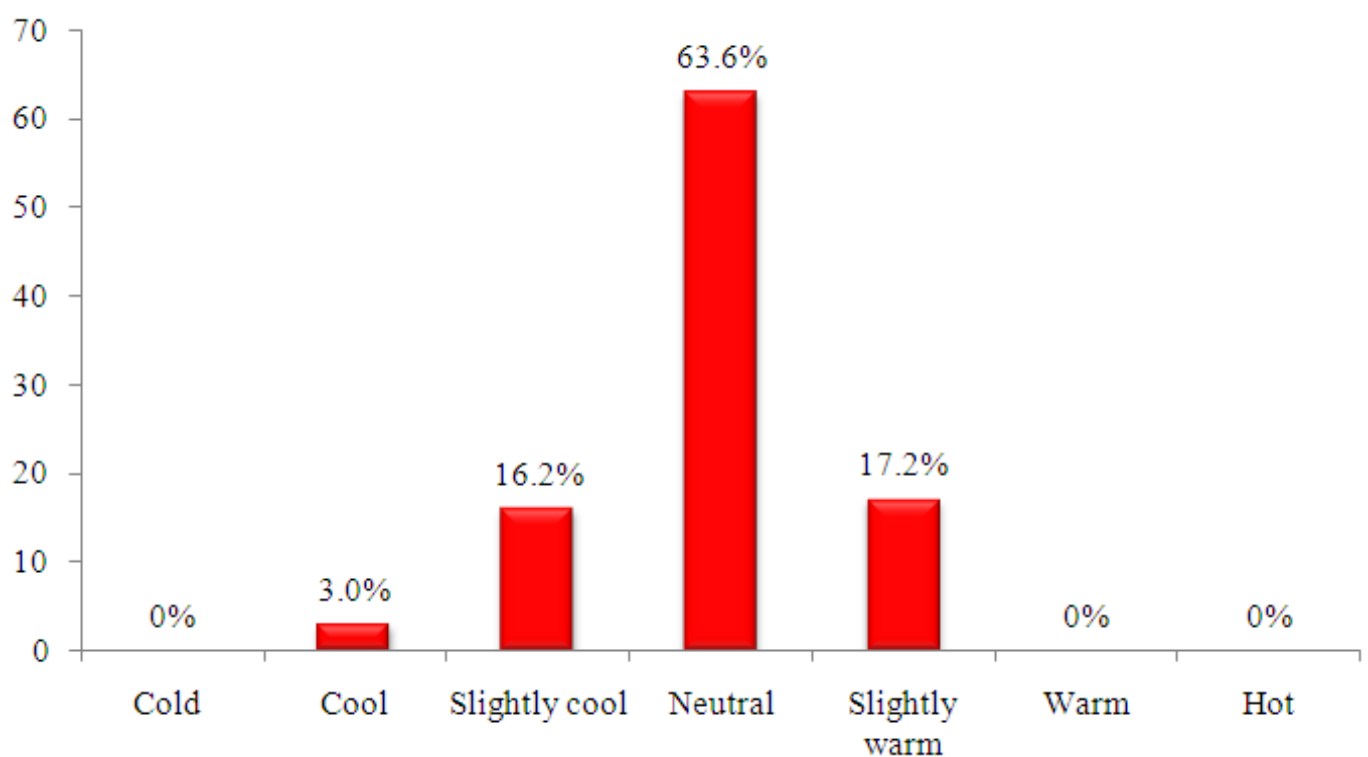

Fig. 2: Thermal Sensation Votes (TSV) results

Figure 3 showed the A 7-points humidity sensation namely called 'Humidity Perception Vote (HPV)' (-3 very dry, -2 dry, -1- slightly dry, 0 just right, 1 slightly humid, 2 humid, 3 very humid) similar to the ASHRAE standard 55, ASHRAE Thermal Sensation Scale. The humidity level inside this LEO building owned by the Ministry of Energy, Green Technology and Water, Malaysia did not exceed the humidity level of between $40-60 \%$ provided by the Department of Occupational, Safety and Health (DOSH) Malaysia, in the Guidelines on Occupational Safety and Health in the Office handbook.

Figure 4 showed the Indoor Draft Perception Vote (DPV) results with a vote of -3 indicates the air velocity level in the building was too low or motionless, a zero vote means that the respondents felt that the air velocity was just right. A small portion of $4 \%$ out of all respondents in this study perceived that the air was too steady or motionless while a large portion of $96 \%$ of respondents accepted the air velocity was just right with all the votes centered between -1 to 1 .

Thermal preference: Thermal preference votes indicate what the respondents preferred to be having in their working office environment. Table 3 showed the association between the thermal sensation and the preference responses from the respondents of the study. 


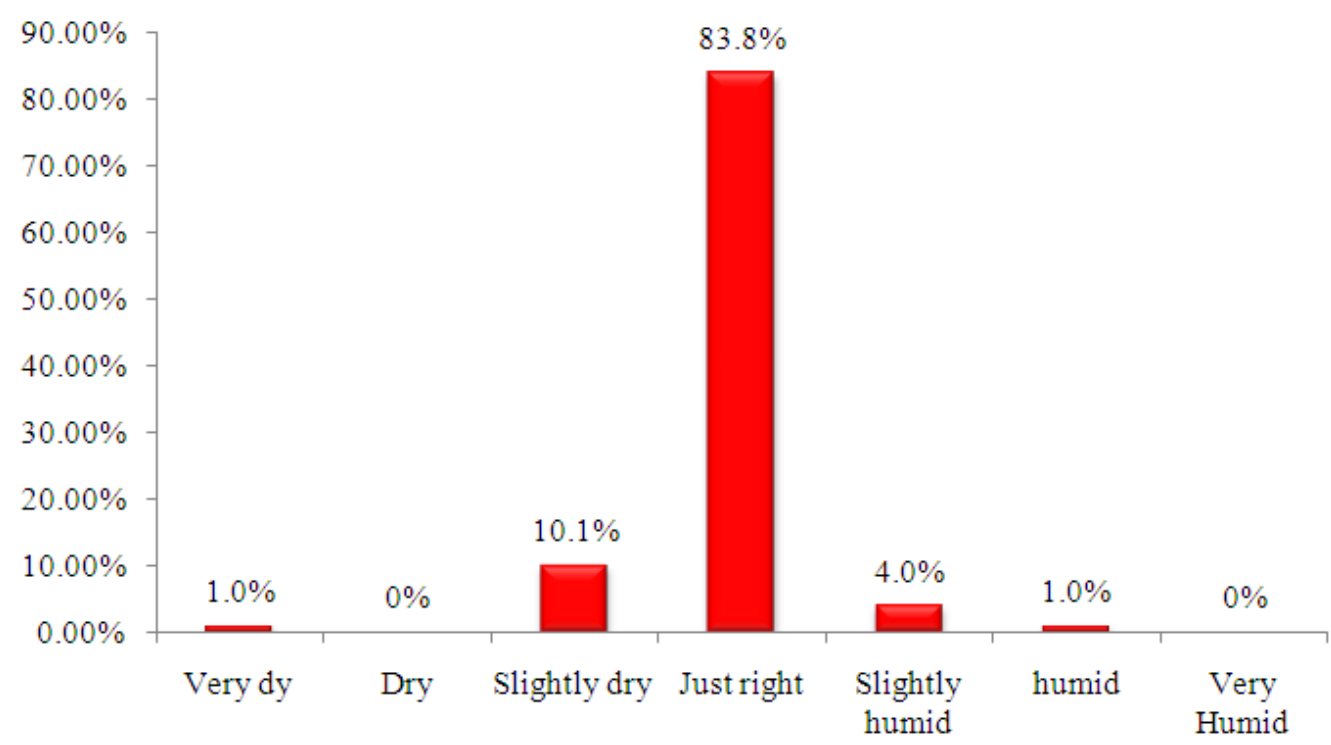

Fig. 3: Indoor Humidity Perception Votes (HPV)

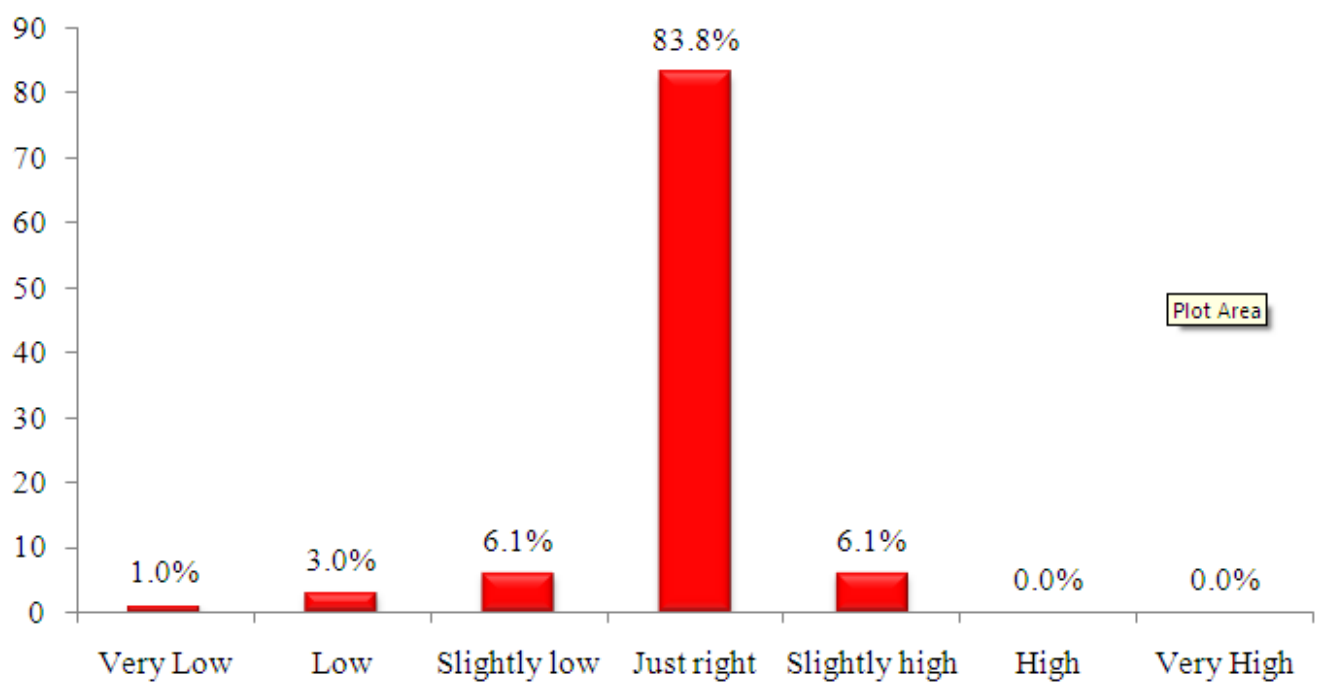

Fig. 4: Indoor Draft Perception Votes (DPV)

Table 3: Association of thermal sensation and preference responses

\begin{tabular}{|c|c|c|c|c|c|}
\hline \multirow{2}{*}{$\begin{array}{l}\text { Thermal preference } \\
\text { parameters }\end{array}$} & \multicolumn{5}{|c|}{ Thermal sensation scale } \\
\hline & -2 & -1 & 0 & 1 & 2 \\
\hline Air temperature & 0 & $17(17.2 \%)$ & $54(54.5 \%)$ & $28(28.3 \%)$ & 0 \\
\hline Relative humidity & 0 & $3(3 \%)$ & $57(57.6 \%)$ & $39(39.4 \%)$ & 0 \\
\hline Air velocity & $4(4.0 \%)$ & $24(24.2 \%)$ & $69(69.7 \%)$ & $2(2 \%)$ & 0 \\
\hline
\end{tabular}

For the indoor air temperature, the thermal sensation scale indicates the value of -2 as more warmer preferred to the value of 2 as more cool preferred by the respondents. Value of -2 indicates the humidity level to be drier and 2 indicates the humidity level to be more humid and for air velocity, the thermal sensation scale of -2 indicate more air movement preferred and 2 more less air movement preferred by the studied respondents. 


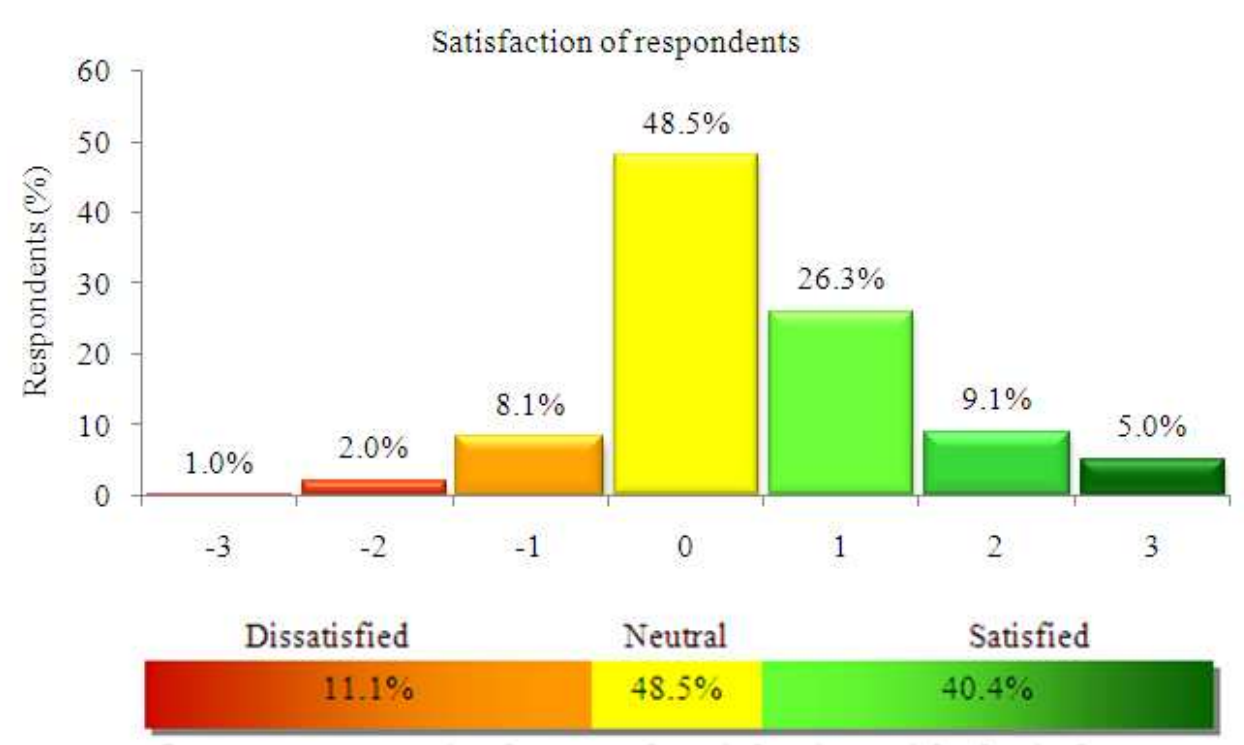

Fig. 5: Occupants perceived general satisfaction with the indoor temperature

Table 4: Association between perceived thermal comfort and calculated PMV

\begin{tabular}{lll}
\hline & Occupants' satisfaction & \\
Perceived thermal & ---------- \\
comfort & $\mathrm{x}^{2}$-value & p-value \\
\hline Thermal sensation & 82.31 & $* 0.001$ \\
Humidity perception & 130.36 & $* 0.001$ \\
Velocity perception & 134.31 & $* 0.001$ \\
\hline
\end{tabular}

Occupants' perceived thermal satisfaction: Figure 5 showed the satisfaction level of all the respondents in LEO building towards the indoor temperature and also to compare the results studied with the ASHRAE Standard 55 thermal comfort condition $(80 \%$ or more of the occupants are satisfied with the temperature). This studied showed, out of all the respondents, only $40.4 \%$ were positively satisfied with the condition, $11.1 \%$ stated their positively dissatisfied and $48.5 \%$ considered the condition inside the building was just right.

Table 4 showed the statistical results in determining the association between perceived thermal comfort that was voted by respondents and the calculated PMV values based on the measured temperature in LEO's Building. This proved that the perceived thermal comfort parameters can influence the workers' satisfaction in LEO building.

\section{DISCUSSION}

Socio demographic: For the purpose of the study, selection of respondents is important. Ninety-nine respondents out of the whole building occupants were selected for this study with the portion of male workers towards female workers was $20.2 \%$ to $79.8 \%$. The selection of respondents was conducted randomly based on work location of the workers who did the clerical and secretarial task in an open arrangement working area. The reason was that when the population in a certain location was high, the acceptability and the perception towards the working environments would be different although they were exposed to the same contributing factors. According to previous studies by Daghigh et al. (2009), the selection of open arrangement area would make the occupants in the area for having the same thermal condition as compared if an occupant working in a closed area (room) because the level of velocity, temperature and humidity level between places are different.

From the survey, $83.8 \%$ of the respondents were aged between early $20-30$ years old and $15.2 \%$ aged between $30-50$ years old. The other $1 \%$ aged above 30 years old. From this percentage it shows that the majority the studied respondents were at young aged during the study was conducted. It has been said that human in a group of early adulthood can adapt faster to the thermal environment compared to those who were at already in the late stage of adulthood. This statement was proved by Sherman (1985).

The association between perceived thermal comforts with perceived occupants' satisfaction: Due to the location of this country which is close to the earth's equator, the temperature range is between $25-35^{\circ} \mathrm{C}$ all over the year. 


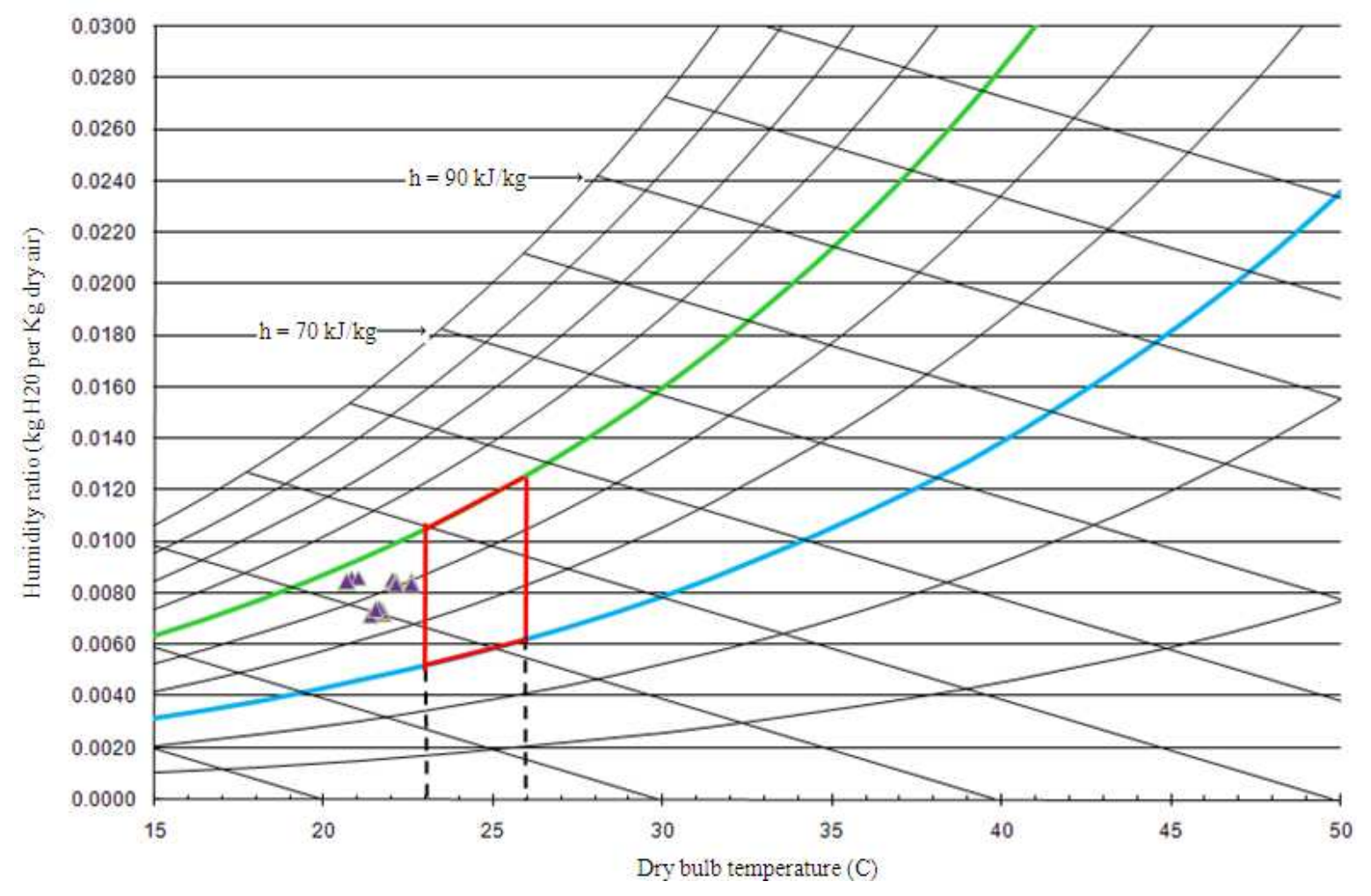

Fig. 6: A comparison of average monitored data from all points in the buildings with ASHRAE Standard 5

The mean temperature is approximately $27^{\circ} \mathrm{C}$. The relative humidity level can raise exceeding $80 \%$ (Ismail et al., 2009). In the effort of knowing the indoor thermal problems inside the LEO building, the occupants must be viewed as important contributors throughout the assessment process as they are the source complaints and a potential source of useful information that can help in assessing the extent of the problem and identifying solutions (Budaiwi, 2007).

Thermal comfort is one of the most significant factors affecting the occupants' environmental satisfaction (Croome and Baizhan, 2000), though it is difficult to satisfy everyone in a space due to biological variation and perception from person to person (ASHRAE, 2004). The studied in a LEO building show that $40.4 \%$ of the respondent satisfied with the current condition and another $48.5 \%$ out of all respondents felt that the condition in the building has been just right. The $11.1 \%$ of the respondents felt dissatisfied with current condition in the building. Therefore it appears that the occupant perceived satisfaction with the temperature is not in compliance with the acceptable thermal satisfaction range within ASHRAE Standard 55 ( $80 \%$ or more of the occupants are satisfied with the temperature).
In determining the association between the perceived thermal comforts with perceived occupants' satisfaction using a statistical test, a chi-square test was used. From the test, it shows that all the perceived thermal comfort parameters which are Thermal Sensation Votes (TSV), indoor Humidity Perception Votes (HPV) and Draft Perception Votes (DPV) shows a significant association with the occupants ' perceived thermal comfort votes with the $p$-value $<0.001$

\section{Compliance with ASHRAE Standard-55 and ISO} 7730: The calculated psychometric chart for the LEO office building studied was shown in Fig. 6, along with the bounds of the ASHRAE Standard 55 comfort zone range. From the figure below, it shows that none of the studied samples were in compliance with the Standard. The entire location sample studied resulted within the acceptable range of relative humidity which was between $30-60 \%$. However, the temperature was a bit lower than the recommended temperature of between $23-36^{\circ} \mathrm{C}$ for the air conditioning office. This result shows that the building occupants felt that the current outdoor temperature was too high which they had to decrease the indoor temperature to achieve comfortability. 
The calculation of the PMV and PPD using Fanger's equation shows that the current condition of LEO building was in the comfort range based on ISO 7730. All the fifteen sampling location shows the compliance with having the temperature within the range provided by the ISO 7730 . This shows that by taking into accounts the measured temperature, metabolic rates and clothing insulation, the degree of occupants comfort level can be determined and comply with the standard.

\section{CONCLUSION}

The results of this study were used to test the hypothesis with the result that there are no significant relationship between the work-related symptoms and thermal environment in the LEO's Building, Putrajaya. The results also suggested that the reported workrelated symptoms of the building occupants, didn't cause by indoor temperature. This was supported by HSE (2008), which suggested that work-related symptoms were not only influenced by temperature but also the condition of Indoor Air Quality (IAQ) of the building. However, there is a positive relationship between measured thermal indoor temperatures with worker satisfaction in LEO building. The calculated values of Predicted Mean Votes (PMV) and Percentage People Dissatisfied (PPD) of measured temperature in Low Energy Office building in Putrajaya comply with ISO 7730 Standard 2005 with the percentage of PPD did not exceed $10 \%$ of all studied respondents, but all the measured indoor temperature in Low Energy Office building in Putrajaya did fall within ASHRAE Standard-55 thermal comfort zone.

Recommendation: Thermal comfort can be defined as a condition of mind which expresses satisfaction with the thermal environment. Due to large variations from person to person, it is difficult to satisfy everyone within the same thermal environment. A comfortable temperature must be maintained and most people work comfortably within temperature between $20-26^{\circ} \mathrm{C}$. According to the national standard provided by the Department of Occupational Safety and Health Malaysia, the optimum comfort range for relative humidity in Malaysia is between $40-60 \%$. If the level of humidity is too high, or too low, the adverse health effect might happen, so ventilation must be adequate for each person at a minimum rate of 10 liters fresh air per second per person for general office space or 10 liters fresh air per second for every 10 square meters of floor space is recommended. Since research regarding association between thermal comfort and health are limited, more study need to be conducts to prove that indoor temperature can have a significant effect of acute and chronic health symptoms.

\section{REFERENCES}

ASHRAE, 2004. Thermal Environmental Conditions for Human Occupancy. 1st Edn., American Society of Heating, USA., pp: 26.

ASHRAE, 2009. 2009 ASHRAE handbook, Fundamentals. 1st Edn., ASHRAE, Atlanta, GA., ISBN: 9781615830015.

Budaiwi, I.M., 2007. An approach to investigate and remedy thermal-comfort problems in buildings. Buil. Environ., 42: 2124-2131. DOI: 10.1016/j.buildenv.2006.03.010

Chen, K., M.J. Rys and E.S. Lee, 2006. Modeling of thermal comfort in air conditioned rooms by fuzzy regression analysis. Math. Comput. Model., 43: 809-819. DOI: 10.1016/j.mcm.2005.06.012

Croome, C. and L. Baizhan, 2000. Productivity and indoor environment. Proc. Heal. Buil., 1: 629-631.

Daghigh, R., N.M. Adam, K. Sopian and B.B. Sahari, 2009. Thermal comfort of an air-conditioned office through different windows-door opening arrangements. Build. Serv. Eng. Res. Technol., 30: 49-63. DOI: 10.1177/0143624408099448

Dahlan, N.D., P.J. Jones, D.K. Alexander, E. Salleh and D. Dixon, 2008. Field measurement and subjects' votes assessment on thermal comfort in high-rise hostels in Malaysia. Indoor Built Environ., 17: 334-345. DOI: 10.1177/1420326X08094585

Fanger, P.O., 1970. Thermal Comfort: Analysis and Applications in Environmental Engineering. 1st Edn., Danish Technical Press, Copenhagen, ISBN10: 8757103410, pp: 244.

HSE, 2008. Thermal Comfort. Health and Safety Executive.

Ismail, A.R., N. Jusoh, K. Sopian, I.M.S. Usman and R. Zulkifli et al., 2009 Thermal comfort assessment: A study at Malaysia car manufacturer. Eur. J. Sci. Res., 27: 510-523.

ISO 7730, 1994. Moderate thermal environments -Determination of the PMV and PPD indices and specification of the conditions for thermal comfort. International Organization for Standardization.

Khalil, N. and H.N. Husin, 2009. Post occupancy evaluation towards indoor environment improvement in Malaysia's Office buildings. J. Sustainable Dev., 2: 186-191. 
MJKKP, 2005. Code of Practice on Indoor Air Quality. 1st Edn., Department of Occupational Safety and Health, Putrajaya, ISBN-10: 9832014514.

Nazanin, N., I. Knight and P. Jones, 2008. Workplace satisfaction and thermal comfort in air conditioned office buildings: Findings from a summer survey and field experiments in Iran. Indoor Built Environ., $\quad 17$ : $\quad 69-79 . \quad$ DOI: 10.1177/1420326X07086945

Sherman, M., 1985. A Simplified model of thermal comfort. Energy Build., 8: 37-50. DOI: 10.1016/0378-7788(85)90013-1
Wagner, A., E. Gossauer, C. Moosmann, T. Gropp and R. Leonhart, 2007. Thermal comfort and workplace occupant satisfaction-results of field studies in German low energy office buildings. Energy Buil., 39: 758-769. DOI:10.1016/j.enbuild.2007.02.013

Wan, M.P. and C.Y. Chao, 2002. Experimental study of thermal comfort in an office environment with an underfloor ventilation system. Indoor Built Environ., 11: 250-265. DOI: 10.1159/000066525 